\title{
Integrated stormwater inflow control for sewers and green structures in urban landscapes
}

Lund, Nadia Schou Vorndran; Borup, Morten; Madsen, Henrik; Mark, Ole; Arnbjerg-Nielsen, Karsten; Mikkelsen, Peter Steen

Published in:

Nature Sustainability

Link to article, DOI:

10.1038/s41893-019-0392-1

Publication date:

2019

Document Version

Peer reviewed version

Link back to DTU Orbit

Citation (APA):

Lund, N. S. V., Borup, M., Madsen, H., Mark, O., Arnbjerg-Nielsen, K., \& Mikkelsen, P. S. (2019). Integrated stormwater inflow control for sewers and green structures in urban landscapes. Nature Sustainability, 2, 10031010. https://doi.org/10.1038/s41893-019-0392-1

\section{General rights}

Copyright and moral rights for the publications made accessible in the public portal are retained by the authors and/or other copyright owners and it is a condition of accessing publications that users recognise and abide by the legal requirements associated with these rights.

- Users may download and print one copy of any publication from the public portal for the purpose of private study or research.

- You may not further distribute the material or use it for any profit-making activity or commercial gain

- You may freely distribute the URL identifying the publication in the public portal 


\title{
Integrated stormwater inflow control for sewers and green structures in urban landscapes
}

\author{
Nadia Schou Vorndran Lund ${ }^{1 *}$, Morten Borup ${ }^{1}$, Henrik Madsen², Ole Mark ${ }^{2}$, Karsten Arnbjerg-Nielsen ${ }^{1}$, Peter Steen \\ Mikkelsen ${ }^{1}$ \\ ${ }^{1}$ Department of Environmental Engineering (DTU Environment), Technical University of Denmark, Bygningstorvet, Building \\ 115, 2800 Kgs. Lyngby, Denmark \\ ${ }^{2} \mathrm{DHI}$, Agern Allé 5, 2970 Hørsholm, Denmark
}

Cities increasingly use real-time control of combined sewer systems and green infrastructure to decrease emissions to surface waters, and incorporate infrastructure into the urban landscape to reduce flooding from cloudbursts, i.e. short-duration, intense rainfall events that can cause flash flooding and disruption of critical functions in the city. Inspired by the 'smart cities' agenda, we propose using integrated stormwater inflow control to dynamically activate cloudburst conveyance infrastructure in the urban landscape as well as green storage elements more often than originally intended. The control facilitates synergy between sewers, green infrastructure and the urban landscape, and has lower environmental impacts than isolated control approaches. A simulated yet realistic case study in Copenhagen, Denmark, shows that combined sewage emissions can be eliminated or reduced substantially in this manner. Other potential benefits include, for example, increasing amenity value and educating citizens. The results suggest that the proposed control concept potentially provides a viable path towards more resilient, liveable and sustainable cities.

Urban water management is challenged by climatic changes that increase both dry and wet spells in cities ${ }^{1}$, and $11-18 \%$ of the money spent on climate change adaptation in megacities is used in the water sector ${ }^{2}$. Although adaptation responses differ globally, much of the current investment is related to urban drainage infrastructure, which represents the most expensive capital investment in infrastructure in the city and the one that is most cost-effective in terms of socio-economic gain $^{3}$. Yet, it remains the type of infrastructure that is deteriorating the most because of its sub-surface status, making it an object of 'out-of-sight, out-of-mind' thinking ${ }^{4}$. Urban drainage infrastructure is complicated and globally diverse as shaped by historical circumstances, and the field is surrounded by linguistic uncertainty and ambiguity 5,6 . Most European city centres have combined sewer systems (carrying both wastewater and stormwater in the same pipe network), a system type dating back to the 1850s when cholera raged in Europe. Australian and some North American cities started infrastructure development later and chose another path by implementing separate sewer systems (carrying wastewater and stormwater in distinct pipe networks). In many cities, like Beijing, San Francisco, and Copenhagen, both types of systems coexist in different city districts, whereby combined systems in the old city centres receive runoff from newer separate systems in the suburbs, which were constructed from the 1950s onwards. The cost and logistics of changing the existing combined sewer systems into two-string systems that separate stormwater and wastewater are often prohibitive ${ }^{7}$.

A main disadvantage of combined sewer systems is that stormwater with a low content of nutrients and pathogens and a high content of some heavy metals and organic micropollutants ${ }^{8,9}$ is mixed with sewage with a very high content of pathogens. Human exposure to this mixture poses an immediate health risk ${ }^{10,11}$. Where possible, combined systems are equipped with detention basins that store combined sewage for later discharge to wastewater treatment plants, as well as combined sewer overflow structures (CSOs) that act as safety valves to prevent flooding of basements and streets at the immediate expense of the water quality in nearby rivers, lakes and coastal areas ${ }^{12,13,14,15}$. Climate change is generally ex-

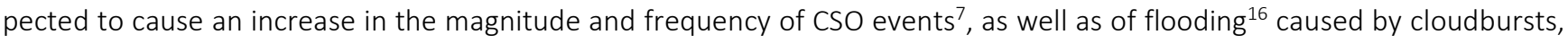
i.e. short-duration, intense rainfall events that can cause flash flooding and disruption of critical functions in the city ${ }^{17}$. Thus, 
we need innovative solutions to address the lock-in of deteriorating performance of existing urban drainage infrastructure. This is in line with Simpson ${ }^{18}$ who highlighted the necessity of 'twenty-first century' approaches to cope with climate changes affecting water.

\section{Green stormwater infrastructure}

This relatively new type of stormwater control measures (SCMs) aims to manage stormwater by using vegetated systems that rely on a combination of detention, infiltration and evapotranspiration. Green stormwater infrastructure (from here on, simply denoted 'green infrastructure') has origins in both landscape architecture and landscape ecology, and was reframed around 2010 to include stormwater management targets (see the discussion in Fletcher et al. ${ }^{5}$ ); it is also part of the newly coined concepts Nature Based Solutions (in Europe) and Sponge Cities (in China). Green infrastructure offers many benefits to urban society, including, for example, reduced CSO frequency and magnitude, reduction of the urban heat island effect and improved urban amenities ${ }^{19,20,21,22,23}$. Besides increasing resilience locally, green infrastructure also results in lower environmental impacts throughout the whole life cycle of the system than those associated with sewer separation and grey infrastructure expansions; this is due to the lesser need for the production of steel, concrete and road materials in particular, as well as reduced fuel consumption, during the construction process ${ }^{24,25}$.

\section{Digital transformation and 'smart cities'}

At the same time, a new digital era is transforming cities into 'smart cities'26, for example, by introducing smart traffic regulation that both increases the capacity and reduces the energy consumption of transportation systems, along with smart lighting that enhances security while reducing the $\mathrm{CO}_{2}$ footprint. The same development towards cyber-physical system integration within the water sector is referred to as, for example, 'data-driven urban water management'27, 'smart water ${ }^{28}$, and 'water $4.0^{\prime 29}$ in a reformulation of the phrase coined by Sedlak ${ }^{30}$. Sedlak originally refered to closing of the water loop, whereas newer literature on water 4.0 mirrors the digitalisation tendency from 'industry 4.0' (used in the manufacturing industry ${ }^{31}$ ). This digitalisation trend is enabled by enhanced data collection from both traditional in-situ sensors and new data sources (for example, remote sensing and crowdsourcing), as well as improved predictive and prescriptive analytics that allow for smarter decision-making in the pursuit of better urban water management ${ }^{27,32}$. This 'smart cities' concept can be used for CSO mitigation through flow regulation that maximises the use of the storage capacity in the combined sewer system ${ }^{6,33}$ or single green infrastructure elements and other $\mathrm{SCMs}^{34,35}$. By utilising existing infrastructure more efficiently through digitalisation, local environmental benefits (such as reduced CSO frequency) can be achieved with lower general environmental impacts caused over the entire life cycle. It is, however, increasingly being acknowledged that conventional combined sewer systems and green infrastructure elements provide limited flood mitigation during cloudbursts because their storage and conveyance capacities are exceeded for these events ${ }^{17,36,37}$.

\section{Cloudburst management}

The city of Copenhagen, Denmark, is a frontrunner in retrofitting combined sewer systems to accommodate new societal demands and new environmental pressures. Construction of large underground detention basins in the city and particularly along the harbour quay in the 1990s has made bathing in the inner city harbour possible, which has contributed to the general increase of liveability in Copenhagen, as documented by its status as one of the most liveable cities in the world ${ }^{38}$. Furthermore, six major cloudbursts in the years 2010-17 have caused the city to develop a solid business case for increasing climate change resilience by altering the urban landscape $e^{36,39,40}$. The implementation calls for the construction of 300 cloudburst management projects with green and grey solutions during the next 20 years. Alteration of the street layout for stormwater storage was implemented in the US for CSO mitigation already in the $1980 \mathrm{~s}^{41,42}$. New York furthermore recently joined Copenhagen in a formal partnership to exchange knowledge on developing a new paradigm for cloudburst resilience where existing grey and green stormwater infrastructure is combined with large-volume surface storage infrastructure and conveyance of excess stormwater along roadways while providing socioecological amenities during normal conditions ${ }^{17}$. We envision that many cities in the coming decades similarly will implement a range of grey and green, multifunctional stormwater infrastructure options ${ }^{37}$, as well as above-ground water conduits or 'water highways', as part of their climate resilience strategy. Drawing upon such new infrastructure elements placed in the urban landscape more often in a dynamically 
controlled manner by tapping into the 'smart cities' agenda, and not just in case of rare cloudburst events, has represented until now an unexploited potential.

\section{A call for synergy}

In this study, we wish to establish the potential for utilising the concept of smart cities to create synergy between green stormwater infrastructure, grey and green cloudburst infrastructure placed in the urban landscape, and the underground combined sewer system to reduce CSOs during minor- and medium-sized rain by performing a smart control of stormwater inflows. Stormwater storage facilities may include skate parks, retention ponds, parking lots, football fields, lawns, etc., and stormwater conveyance routes may include regular streets and cloudburst roads designed to accommodate an acceptable inundation level, in Copenhagen chosen as $10 \mathrm{~cm}$ for a 100-year event, without disrupting traffic ${ }^{36,17}$. Hereby, the multifunctionality, and thus the resilience, of the city increase ${ }^{43}$. By including the entire urban landscape, we increase the area available for stormwater management while at the same time ensuring that stormwater becomes visible throughout the city. This may not only create amenity value, even in areas without green infrastructure, but can also serve to educate the population about the cause-effect relationships among rain, stormwater, CSOs, and the use of the urban landscape for storage and conveyance. An additional positive side effect is that the usage of the cloudburst infrastructure on a more frequent basis may raise awareness of its purpose, thus counteracting the current 'out-of-sight, out-of-mind' thinking ${ }^{4}$, and ensure that the cloudburst infrastructure actually functions when the rare cloudburst events take place.

We elaborate and discuss the concept and benefits of smart control of stormwater inflows that enables the utilisation of the sewer system, green infrastructure (and other SCMs) and the urban landscape adapted for cloudburst management to minimise CSO while also addressing impediments to implementation. Rather than only discussing the proposed integrated stormwater inflow control conceptually and theoretically, we provide a concrete and practical example to illustrate the perspective. This proof-of-concept simulation study contains a single cloudburst management project in Copenhagen, in an area suffering from flooding and too-frequent CSOs, and concretise the advantages of jointly controlling the underground sewer system, a green infrastructure element designed to store stormwater and accommodate flooding with only little or no associated damage, and a 'water highway' designed to safely convey large amounts of stormwater. The use of model predictive control (MPC) and weather forecasts will be key elements in the proposed concept, see Box 1. We subsequently discuss practical considerations and obstacles to implementation including a need for technical innovation, and hypothesise how this concept could be expanded to achieve a wide range of operational goals besides overflow minimisation for combined systems, ultimately bringing us closer to obtaining more liveable, sustainable and resilient cities.

\section{Box 1 | Model prediction control.}

Model prediction control (MPC) is used in many technologies that tap into the 'smart cities' agenda, for example, smart energy systems ${ }^{59}$, smart transportation ${ }^{60}$, and smart water systems $s^{6}$. This paper presents a novel application of MPC in the field of urban drainage that takes advantage of cloudburst conveyance infrastructure in the urban landscape and achieves synergies with sewer systems and green infrastructure to obtain additional environmental benefits. In this context, MPC requires weather forecasts, which allows for proactive decision-making, and a model of the considered system (the internal MPC model), which should be simple enough to allow the optimisation to be run in real time. The optimisation is performed over a given prediction horizon based on a set of objectives weighted according to their relative importance. The optimised control is implemented in physical actuators, such as gates and pumps. After a certain sampling interval, the optimisation is redone with new weather forecasts and an updated internal MPC model to ensure that the control is continually adapted to changes in the system and information from new forecasts. 


\section{Integrated stormwater inflow control}

The proposed concept of integrated stormwater inflow control differs from existing concepts.

\section{The proposed concept}

Flow regulation of stormwater systems and combined urban drainage systems uses either 'passive control' (the maximum flow rate is fixed) or 'real-time control' (the flow rate is adjustable). The latter can be implemented either as heuristic rules or more advanced strategies, such as MPC. The underlying idea of the proposed integrated stormwater inflow control concept is that we can use real-time control to proactively decide whether stormwater runoff should enter the combined sewer system or instead be conveyed on cloudburst roads and stored in above-ground SCMs, including green infrastructure elements, by controlling stormwater inflows, hereunder closing or opening stormwater inlets on the streets. The inclusion of the urban landscape creates a dynamic link between single SCM elements and the underground sewer system. The significance of the proposed control is greatest if the runoff from all impermeable surfaces is controlled, including both pavements and roof surfaces, and we hypothesise that the necessary controllable actuators will be developed (discussed in more detail later on). Fig. 1c shows the area of influence of the proposed concept, where control of stormwater inflows to the combined sewer system allows us to jointly optimize the use of the sewer system, the urban landscape and SCMs for storage and conveyance of stormwater, differentiating it from existing stormwater control approaches presented in Fig. 1a and Fig. 1b.

\section{Existing concepts}

Fig. 1a shows the area of influence of real-time control of the underground sewer system. Here, runoff from all impermeable surfaces is allowed into the sewer system, which is equipped with sensors (not shown) and actuators (one shown) to utilise the available storage volume better. Since sewers span whole cities, a system-wide control perspective may be taken. However, this requires dynamic forecasting and optimisation to account for, for example, spatially distributed rainfall. In Fig. 1b, different types of single SCMs are controlled. The outflow from these is usually controlled passively, but there are examples of real-time control both of how much stormwater enters the SCM (for example, runoff from a regular roof onto a green roof or into a rainwater harvesting system) and how much stormwater is discharged from the SCM to the sewer network ${ }^{35,44}$ or to natural recipients ${ }^{34,45}$. Literature on control of SCMs, however, mainly considers the control of single elements and not entire systems ${ }^{46}$.

\section{Comparison}

Existing, more traditional control concepts (Fig. 1a and Fig. 1b) are often limited to operating solely within the technical grey and green infrastructure regime, which is designed for minor- and medium-sized rain events. During major rain events, the system capacity is exceeded and real-time control cannot reduce the overflow. The proposed control concept (Fig. 1c) allows for the addition of using the urban landscape in a safe and intended manner, which significantly expands the capacity for conveyance and storage. Fig. 2 shows conceptually the reduction in CSO volume that can be achieved by traditional control concepts and the proposed control. CSO can be reduced, possibly even eliminated, for minor- and medium-sized rain events by both traditional control and the proposed control concept. However, the performance of traditional control diminishes with the size of the rain event; at a certain point, the entire system is saturated, and traditional control therefore no longer has an effect, thus approaching a zero percent reduction. The shape of the traditional control curve in Fig. $2 a$ is well-known from recent literature ${ }^{47}$. Dynamic control of stormwater inflows that activates the urban landscape is due to the increased capacity much more effective for major rain events. The prevention of stormwater inflow from the entire catchment by, for example, closing stormwater inlets would avoid all CSO. If only parts of the urban surface area are activated for stormwater control, then the CSO reduction will approach the size of this area relative to the entire area, see Fig. $2 \mathrm{~b}$.

\section{Need for trade-off specification}

The proposed control includes the urban landscape as an active part of the stormwater infrastructure, although the primary function of this infrastructure is different. This both allows for and requires an explicit quantification of trade-offs between different usages of the urban landscape and hence that the interests of different stakeholders are included in the control optimisation. Hereby, the trade-offs become negotiable across different stakeholder groups instead of being ignored and hence excluded from any systematic analysis. 


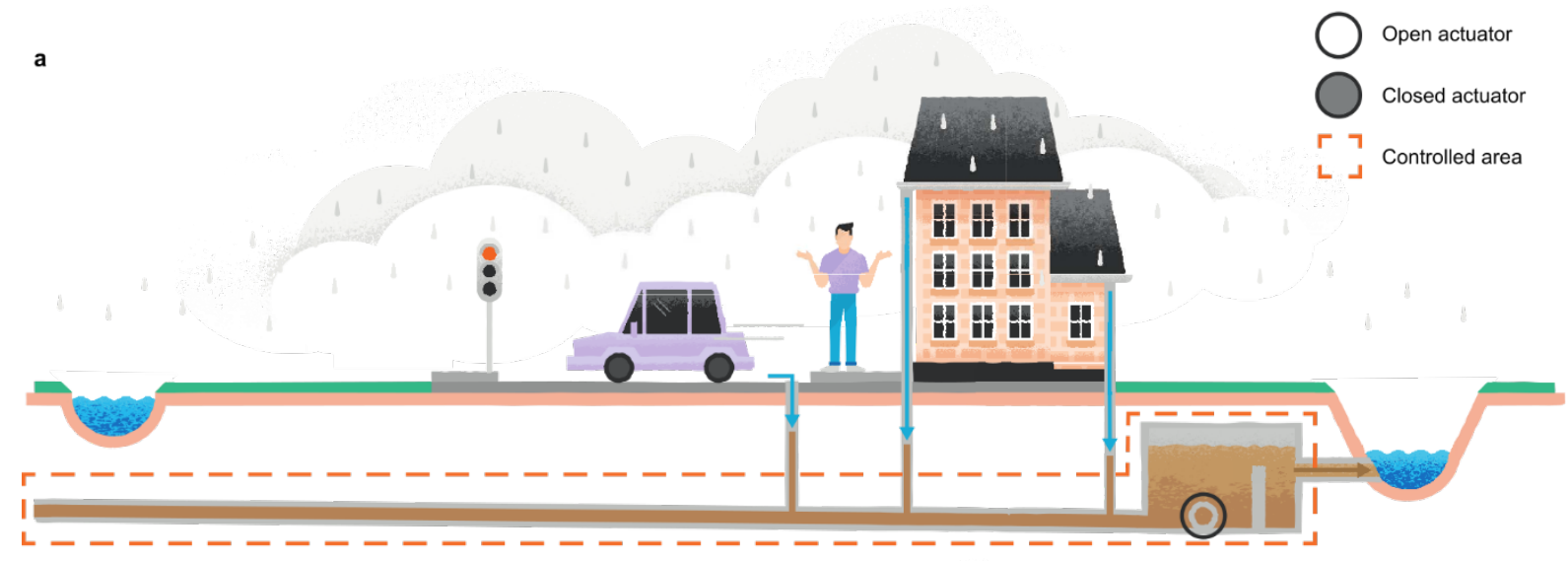

b

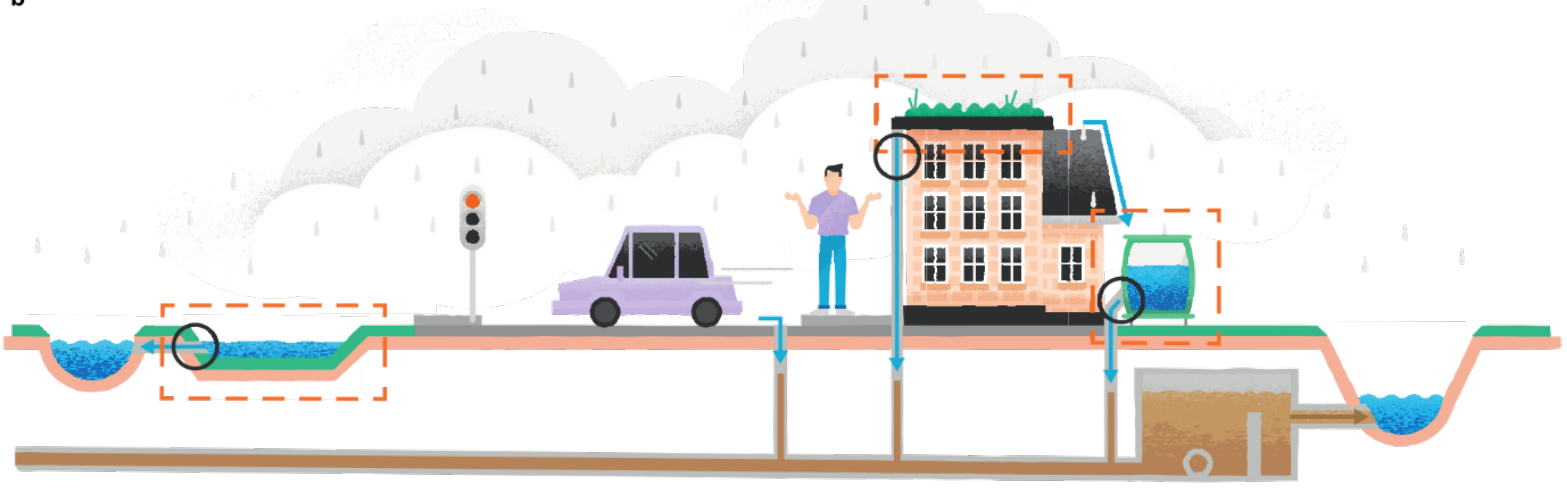

c

Fig. 1 | Illustration of key control concepts discussed in the paper. Existing control of (a) combined sewer systems and (b) single SCM elements, and (c) the proposed integrated stormwater inflow control. The overall illustration is a cross section of an urban area comprising a green area, a traffic area (with a traffic light and a car) and a house, surrounded by small watercourses to the left and right, and served by an underground combined sewer system from which sewage potentially overflows to the rightmost watercourse when the underground system capacity is exceeded. The locations of the main actuators (circles) and the controllable areas (orange dashed polygons) are indicated for each control concept, where (a) takes a system-wide perspective of the whole underground sewer system, (b) focuses on individual SCMs, including green infrastructure elements, placed above ground, and (c) activates stormwater inflow control (closed actuators) while keeping the system-wide perspective in order to minimise, or even avoid, CSO (the other actuators shown could also be used, but are not included in the simulation example). 


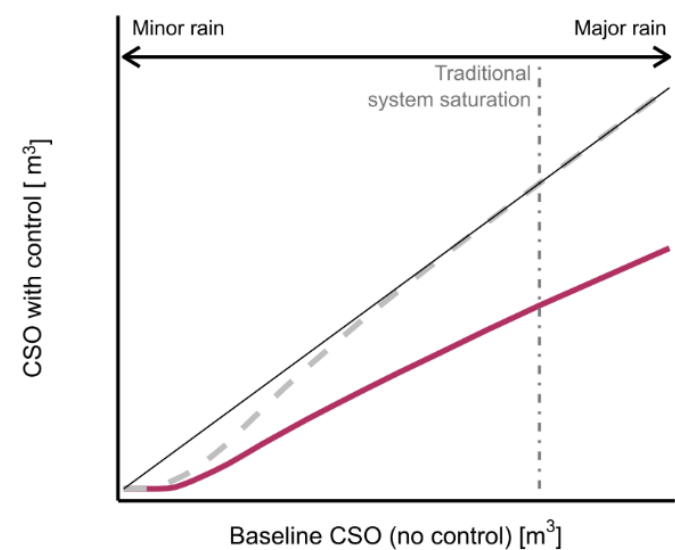

b

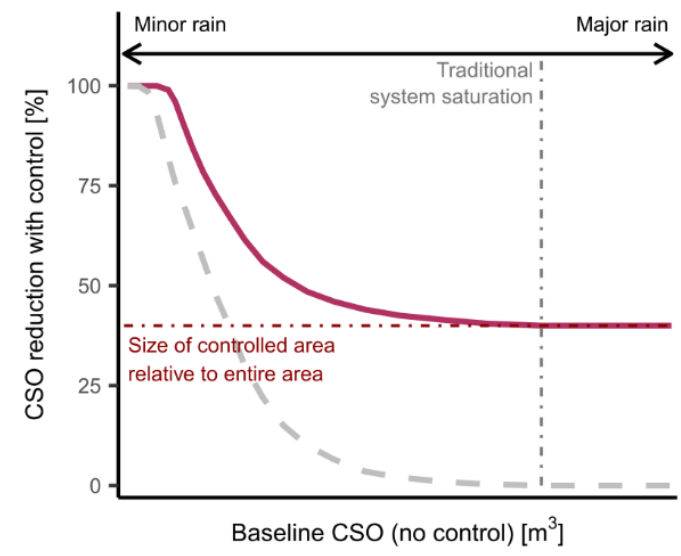

Fig. 2 | Conceptual performance of the proposed versus existing, more traditional control concepts. (a) CSO volume and (b) percentage CSO reduction.

These trade-offs will be dynamic because the many uses of the urban landscape vary over time. We anticipate dynamics due to, for example, variations in amenity use and traffic loading, seasonal variation of vulnerability of ecosystems in green areas, etc. The proposed control concept can incorporate these dynamics as well as the present state of the urban landscape into the control strategy, while still aiming at preventing CSO. The system boundaries will be context dependent and the control concept and trade-offs should thus be modified to meet local needs. The control optimisation could also, for example, constrain the maximum retention time of stormwater to minimise mosquito breeding ${ }^{34}$ and include how the water depth and velocity compromises the safety of humans ${ }^{48,49}$. If soil moisture is monitored in green areas with relatively large infiltration capacities (for example, green infrastructure), the control concept can take this infiltration capacity into account and stormwater can, for example, be kept in private gardens before the roads and public storage spaces are utilised. Similarly, in wet situations the control can proactively account for the additional runoff from green areas when these have reached saturation. Additionally, we may take the dynamics of water quality of stormwater into account ${ }^{47}$.

Balancing these contrasting usages of the urban landscape is a challenge with no easy solution. Accordingly, the current implementation schemes of Nature Based Solutions have highlighted the struggle inherent in making clear decisions on priorities for the uses of multifunctional spaces, even in cases where no dynamic control is anticipated ${ }^{50}$. The reluctance by some stakeholders to make such clear and transparent decisions should not be underestimated; indeed, even the operators of urban water management systems may pose a significant obstacle ${ }^{6}$. A major task thus seems to be how to enable transparent decision-making across multifunctional spaces. This requires both a deeper understanding of the needs of all users of such spaces, as well as methods for balancing these needs in a quantifiable manner.

\section{Simulation example}

A simulation example is used to concretise the potential benefits of integrated stormwater inflow control.

\section{Case study area}

The 300 cloudburst management projects in Copenhagen contain five main cloudburst elements: cloudburst roads, retention roads, retention spaces, green roads and cloudburst pipes ${ }^{39}$. We have evaluated the concept for one of these planned cloudburst management projects in Copenhagen, which suffers from flooding and too-frequent CSOs, in a proof-of-concept simulation study. The wastewater treatment plant is too far downstream of the case area to merit inclusion in the control. The CSO volume is used as the key performance indicator to exemplify the potential of the proposed control concept.

Fig. 3 shows the study area consisting of a cloudburst road ('water highway') that leads water to a green infrastructure element in a designated section of a large park (Damhusengen), which will function as a retention space in case of cloudbursts. Cloudburst roads will typically be designed using $2 \mathrm{D}$ hydraulics software ${ }^{51}$ for simulating overland flows to ensure that the roads can accommodate an acceptable inundation level for the very rare cloudburst events. We therefore assume that the water velocity and depth on the cloudburst infrastructure in Copenhagen will also be safe for the more frequently 
occurring minor and medium-sized events causing CSO. Stormwater normally enters the underground combined urban drainage system through stormwater inlets, and combined sewage is discharged to a nearby stream when the underground system capacity is exceeded. The CSO structure receives stormwater runoff and wastewater from a total area of $1.5 \mathrm{~km}^{2}$, of which $7 \%$ makes up the catchments connected to the pipe below the cloudburst road (the 'controllable area' that can be dynamically disconnected). In the following, we assume that we can control whether stormwater from the $7 \%$ will enter the sewer system or be conveyed on terrain and stored in the green retention space. In this example, the stormwater (and wastewater) entering the sewer system from the remaining $93 \%$ of the area cannot be controlled.
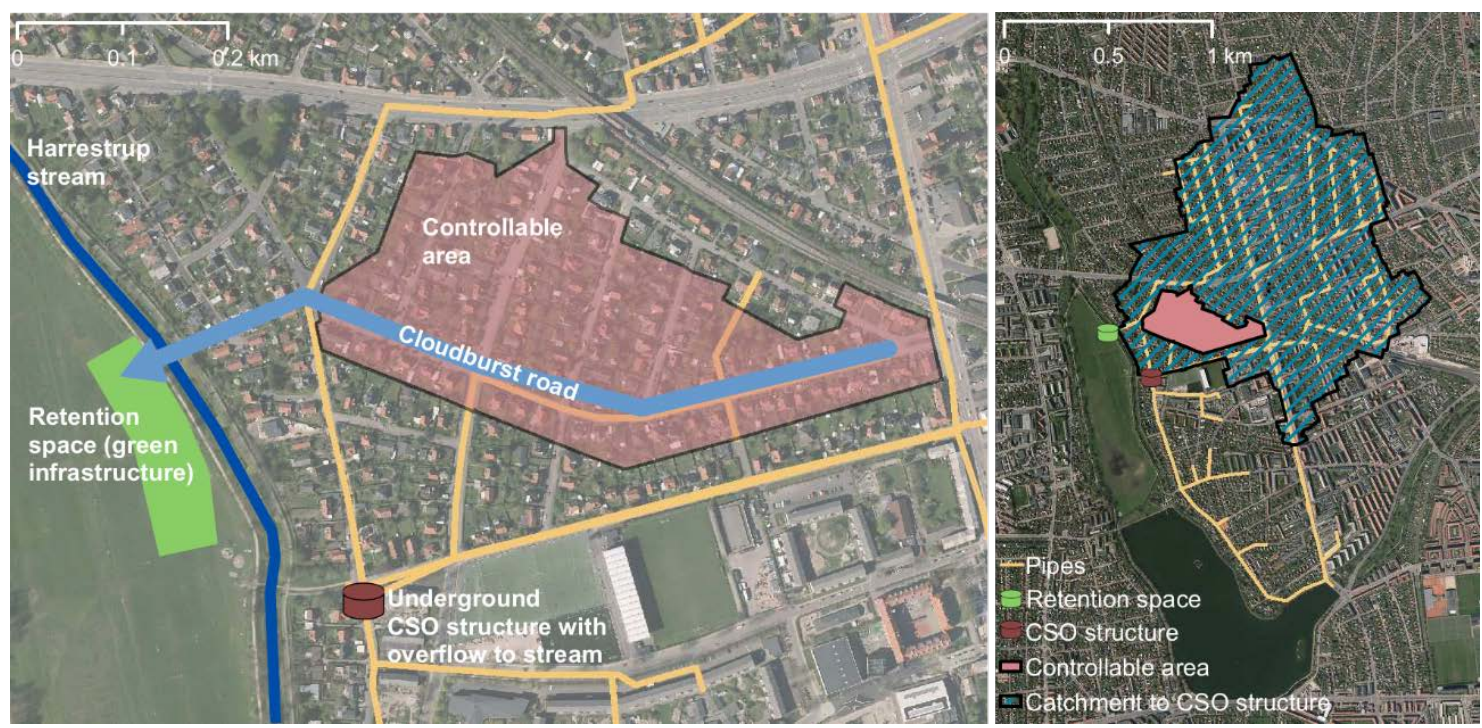

Fig. 3 | Case study area. Left: Cloudburst solutions and sewer system in the controllable area. Right: Total area that discharges water to the CSO structure, and the location of the controllable area herein. Contains data from The Danish Agency for Data Supply and Efficiency, Map 6170_710, November 2016.

\section{The control approach}

We use the MPC framework described in Madsen et al. ${ }^{52}$ to determine how much stormwater should be allowed through the inlets to the sewer system and to control the pumping of stormwater from the retention space back into the combined sewer system. MPC should ensure that stormwater follows the normal pathway through the sewer system when no combined sewer overflow is forecasted to ensure treatment at the wastewater plant. In case of a threat of CSO, the control should prevent stormwater from entering the combined sewer system and instead let it flow onto the cloudburst road, subsequently to be stored in the retention space. The stored water is pumped to the sewer system from the retention space when there is available capacity and a dry period is forecasted. We use historical rain observations as forecasted input (ex-post forecast analysis), thus disregarding uncertainties related to rainfall forecasting. The internal MPC model describes the flows and storage properties of the above- and below-ground system. We do not consider the stormwater runoff contribution from permeable surfaces in this proof-of-concept study. For simplicity's sake, the downspouts are permanently disconnected from the sewer system in the model and instead directed to the cloudburst road with the remaining stormwater, from where it can either enter through the inlets or be conveyed along the road to the retention space. Infiltration and evapotranspiration are assumed to be negligible due to the quick emptying of the retention space and the large water volumes. The optimal settings for the inlets and pump are chosen based on the ones that minimise the CSO volume in the internal MPC model. This optimisation is performed two hours into the future, since this is the range in which we can realistically obtain useful radar-based rainfall forecasts ${ }^{53}$. The optimised control signals from the first five minutes are sent as set-points to the pump and inlets in a detailed 1D hydrodynamic model representing the sewer system and terrain. A 1D model allows us to emulate a real operational system in a realistic manner since the stormwater flow paths are already known from the 2D simulation results obtained in the design phase ${ }^{51}$. The results from the $1 \mathrm{D}$ model simulation are then used to initialise the internal MPC model before a new optimisation is done, again two hours into the future. This exchange of information and the re-optimisation every five minutes correspond to the receding horizon principle of MPC. 


\section{Results}

The impact is tested by using 32 rain events from 2016: the 18 rain events that resulted in CSO and the 14 largest non-CSOproducing rain events. Fig. 4 shows the rainfall intensities for these events, along with the modelled CSO volume in the current situation, where no control or surface solutions are used. Three scenarios are compared:

Current situation (baseline scenario): The inlets are always open, and stormwater never flows to the retention space, i.e. no control.

Integrated stormwater inflow control (scenario 1): The proposed control strategy, wherein the inlets and pump are controlled dynamically by MPC.

Maximum CSO reduction (scenario 2): All stormwater from the controllable area is kept on terrain; thus, none of the 7\% runoff is allowed into the sewer system. This represents the maximum achievable reduction in CSO volume for the integrated stormwater inflow control using the area connected to the cloudburst road.

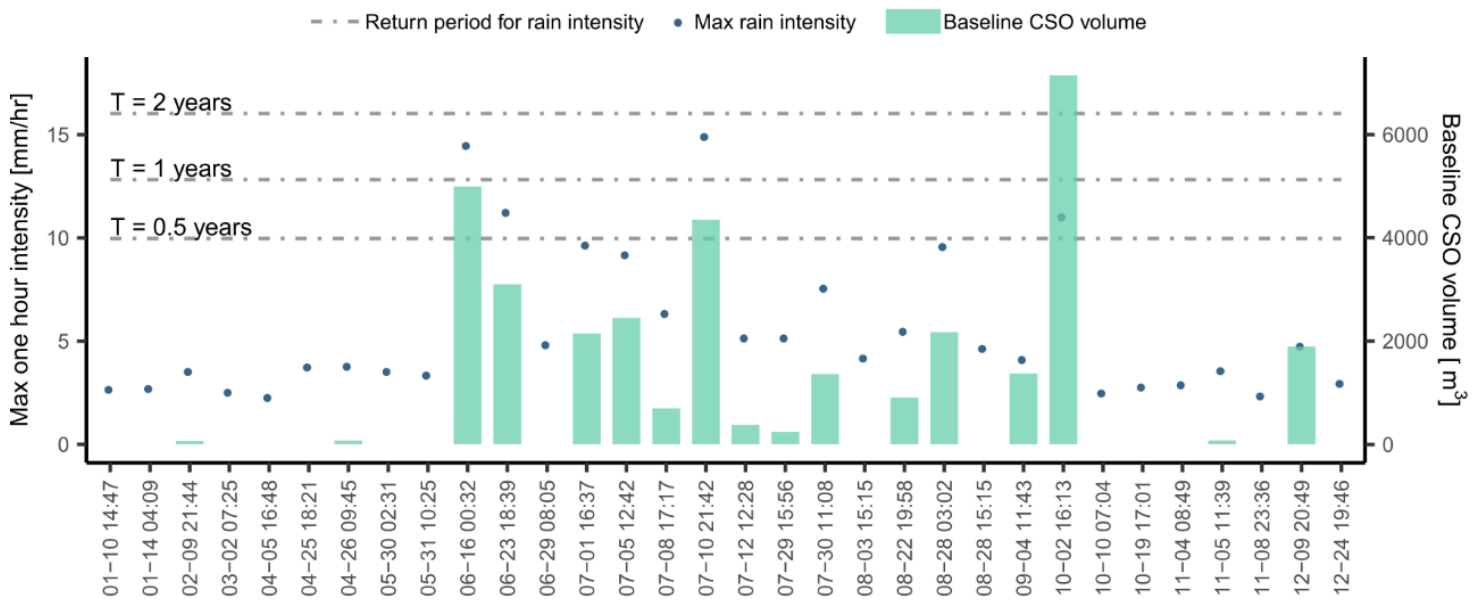

Fig. 4 | Applied rain events from 2016 and CSO emissions. The horizontal axis indicates dates for each event, the left vertical axis indicates the maximum one-hour intensity for each rain event, and the right vertical axis indicates the corresponding CSO volume for each event in the baseline scenario. The dashed-dotted horizontal lines indicate maximum one-hour intensities for statistical return periods $(T)$ of $0.5,1$ and 2 years in the case study area.

Fig. 5 compares integrated stormwater inflow control (scenario 1) and the maximum CSO reduction (scenario 2) with the current situation (baseline scenario) for the 18 CSO-producing rain events and reflects the tendencies from Fig. 2 . Even with an objective function that contains only CSO minimisation, the obtainable reduction depends on several characteristics of the rainfall and the system. Hence, the possible reduction will not strictly decrease with increasing baseline CSO. Scenario 1 enables complete reduction of CSO for the four smallest CSO events, which were the only avoidable events according to scenario 2. This is important since even small CSO events can have severe local consequences. Overall, we obtain an average reduction in CSO volume with integrated stormwater inflow control of $12.4 \%$, corresponding to $98.4 \%$ of the maximum achievable CSO reduction (scenario 2). We also see that the CSO reduction as expected approaches $7 \%$ for the largest events, as only $7 \%$ of the total area is used to manage stormwater on terrain, and a similar reduction is therefore expected also for larger events than those included in this study. In all events, stormwater is delayed less than 24 hours on terrain, and most of this time the stormwater is stored in the green retention space.

The smaller non-CSO-producing events were included in the study to test whether or not the control would lead to unintended CSO. The simulations verified that this did not occur, but in one case the inlets closed and hence water was conveyed on terrain because the MPC falsely predicted an exceedance of the CSO structure capacity. This occurred because of the highly non-linear behaviour of the system, which led to suboptimal set-points for the control and, more generally, highlights the trade-off between reducing CSO volume and the risk of unnecessarily conveying and storing water on terrain. The MPC algorithm can and should be fine-tuned to consider this aspect during the implementation of the control concept. 


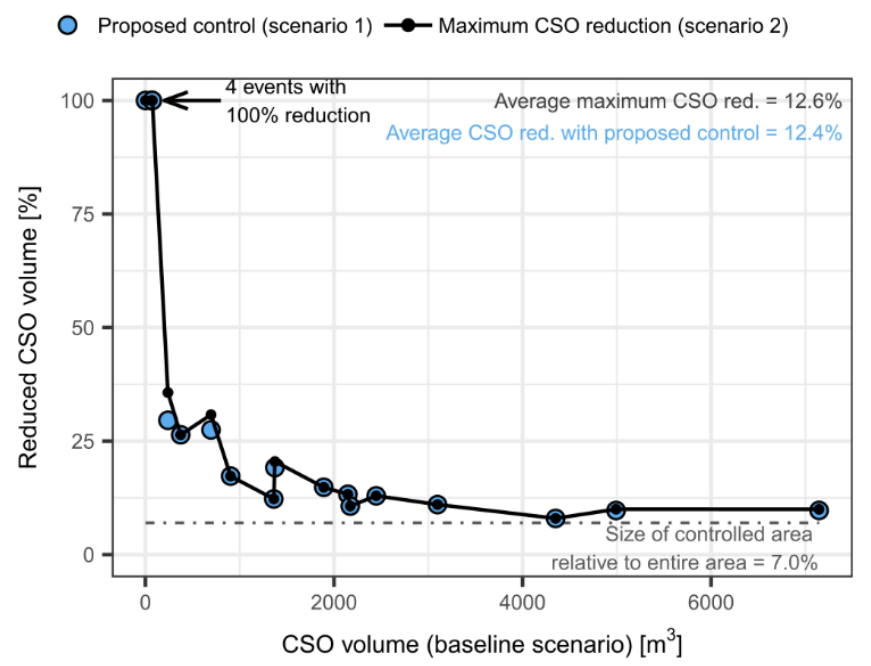

Fig. 5 | Simulated percentage CSO volume reduction. Comparison of the proposed integrated stormwater control (scenario 1) and the maximum CSO reduction (scenario 2) with the current situation (baseline scenario) for the 18 CSO-producing rain events.

\section{Impediments to implementation}

Certain aspects of the proposed concept need further attention before it can be implemented in an operational setting. These impediments include technical aspects, as well as economic, social and regulatory considerations.

\section{Control algorithms}

Algorithms for controlling stormwater inflows need attention over the coming years. Research on the use of MPC within urban drainage has grown rapidly over the last decade, but MPC has been implemented in only a few locations ${ }^{6,33}$. There is not yet consensus on which MPC approach is best for which conditions, and research on how to move from theory to practice is still missing ${ }^{6}$. We anticipate that research in the coming years and decades will enable development of the control software to a fully mature state. In the case study, the model assumptions in the MPC led to suboptimal performance in one out of 32 events. This will be further exacerbated in real-life applications using uncertain forecasts.

\section{Actuators for control of stormwater inflows}

Dynamically controllable stormwater inflow pathways such as downspouts and stormwater inlets need to be developed. Manually adjustable flow regulators in gully pots (catch basins) and downspouts permanently disconnected from the sewer system have already been reported in the literature ${ }^{41,42}$. In these instances, the roof runoff was instead redirected either to green spaces on the property for infiltration or to landscapes angled towards the controlled streets. The disconnection of downspouts was reported to help educate homeowners about the effects of stormwater movement ${ }^{42}$. Recently, a 'cloudburst valve' was introduced that automatically decouples a downspout from the sewer system when the runoff reaches a given flow threshold ${ }^{54}$. We therefore expect that fully dynamic devices for controlling stormwater inflows will be available in the near future.

\section{Costs}

The cost of implementing integrated control of stormwater should be compared with that of alternative solutions. Such a comparison has not been made yet, but implementing passive street storage in two locations was calculated to be $43 \%$ and $38 \%$ of the next-best options (construction of additional sewer pipes (relief sewers) and sewer system separation, respectively $)^{42}$. Even though the cost will differ depending on the location, we assume that these calculations may be used as guidance. Drawing upon already existing, or planned, cloudburst infrastructure for conveyance and storage will diminish the estimated cost significantly, as most of the cost for passive street storage was linked to altering existing streets and pipes. Making a dynamic, real-time control would, however, entail costs related to the use of electricity. Overall, the proposed control likely presents a more economically sustainable option compared to construction of additional grey infrastructure. 


\section{Citizens' acceptance}

The closure of stormwater inlets will result in the deliberate flooding of designated areas, which also serve other purposes such as transportation and recreation. The choice of using the streets and other surface infrastructure for stormwater management will cause nuisance to some citizens while benefitting others, as well as the environment. Acceptance of such an approach requires significant involvement of the local community ${ }^{41,42}$ as well as the explicit quantification of communicable and commonly accepted trade-offs between the benefits and nuisances of water management and other usages of the urban landscape, as described previously. However, there is an often-ignored benefit of these discussions: making the choices of stormwater management transparent and relevant for citizens is in itself a benefit, as they may then more easily accept the trade-offs. The involvement of citizens from the beginning of the project will also make it possible to respond proactively to their concerns by, for example, explaining that streets often flood uncontrollably and that controlled flooding of streets is preferable to, for example, basement flooding ${ }^{42}$. Further, the urban landscape itself can be designed such that the flow and storage of stormwater produces the smallest possible nuisance. For example, the city of Middelfart, Denmark, has permanently closed all stormwater inlets in parts of the town and redirects stormwater on the streets to the nearest water recipient while focusing on accessibility as well as amenity value for citizens ${ }^{55}$. We assume that citizens will also accept a dynamic version of such static control concepts.

\section{Regulatory obstacles}

Current rules and regulations can pose a challenge for the implementation of the proposed control, since these typically focus on avoiding stormwater on the surface while the proposed concept deliberately incites this. Furthermore, seen from a legal perspective, a difference exists between doing something on purpose to protect the environment (for example, provoking stormwater onto the streets) compared with responding to events that are out of our control (such as flooding or CSO events due to insufficient capacity in the sewer system). Additionally, the conveyance and storage of polluted stormwater on surfaces primarily intended for purposes other than stormwater management might also meet opposition. Frontier cities in the US ${ }^{41,42}$ and Denmark ${ }^{55}$ making use of the urban landscape for stormwater management show that these regulatory issues can be solved by focusing on the major environmental and economic benefits from including surface structures in stormwater control.

\section{Implications for urban stormwater management}

The simulation study avoided CSO in four out of 18 events and on average reduced the CSO volume with $12.4 \%$ even though only $7 \%$ of the catchment area was controlled. Expanding the integrated stormwater inflow control concept to the city-wide scale thus has the potential to increase the environmental health of nearby surface waters in an environmentally sustainable way. We suggest that this will also hold true for other types of systems than combined sewers. The past decades have shown a trend towards more complex urban water management with larger systems comprised of a mixture of centralised and decentralised elements, for example, decentralised waste water treatment, sewer system separation, direct water reuse for different purposes, etc., as a result of both technological push and consumer pull. These elements focus on diverse objectives ranging from the very concrete goals of, for example, CSO reduction, water quality improvement, avoidance of uncontrolled flooding of streets and basements, water reclamation for on-site use, and increased groundwater recharge, to the quite diffuse goal of increasing liveability and resilience ${ }^{56,57}$. At the same time, more and more people are moving to cities, with the UN estimating that by 2050 almost $70 \%$ of the global population will live in urban areas ${ }^{58}$. Allocating space for mono-functional stormwater management will thus be challenging. We hypothesise that the more complex the urban water management system becomes and the greater the fight for space, the higher the requirement will be for exploiting synergy through dynamic control of the overall allocation of water depending on local needs, such as the integrated stormwater inflow control concept proposed in this paper. By expanding the concept beyond combined sewer systems, we combine the concept of holistic urban water management with the digitalisation agenda, thus merging the two different water 4.0 concepts $^{29,30}$ into one vision. The benefits of a smarter integrated control of urban water systems thus potentially offer a viable path towards obtaining a better environment both for humans and nature. 


\section{References}

1. Field, C.B. et al. (eds). Managing the Risks of Extreme Events and Disasters to Advance Climate Change Adaptation. A Special Report of Working Groups I and II of the Intergovernmental Panel on Climate Change (Cambridge Univ. Press, 2012).

2. Georgeson, L., Maslin, M., Poessinouw, M. \& Howard, S. Adaptation responses to climate change differ between global megacities. Nat. Clim. Change. 6, 584-589 (2016).

3. Hutton, G., Haller, L. \& Bartram, J. Global cost-benefit analysis of water supply and sanitation interventions. J. Water Health 5, 481-502 (2007).

4. Chocat, B. et al. Toward the sustainable management of urban storm-water. Indoor Built Environ. 16(3), $273-285$ (2007).

5. Fletcher, T.D. et al. SUDS, LID, BMPs, WSUD and more - The evolution and application of terminology surrounding urban drainage. Urban Water J. 12, 525-542 (2015).

6. Lund, N., Falk, A.K., Borup, M., Madsen, H. \& Mikkelsen, P.S. Model predictive control of urban drainage systems: a review and perspective towards smart real-time water management. Crit. Rev. Environ. Sci. Technol. 48, 279-339 (2018).

7. Semadeni-Davies, A., Hernebring, C., Svensson, G. \& Gustafsson, L.-G. The impacts of climate change and urbanisation on drainage in Helsingborg, Sweden: combined sewer system. J. Hydrol. 350, 100-113 (2008).

8. Eriksson, E. et al. Selected stormwater priority pollutants - a European perspective. Science Total Environ. 383, 41-51 (2007).

9. Young, A., Kochenkov, V., McIntyre, J.K., Stark, J.D. \& Coffin, A.B. Urban stormwater runoff negatively impacts lateral line development in larval zebrafish and salmon embryos. Sci. Rep. 8, 2830 (2018).

10. van Bijnen, M., Korving, H., Langeveld, J. \& Clemens, F. Quantitative impact assessment of sewer condition on health risk. Water 10 , 245 (2018).

11. Mark O. et al. A new methodology for modelling of health risk from urban flooding exemplified by cholera - Case Dhaka, Bangladesh. J. Flood Risk Manag. 11, 28-42 (2015).

12. Casadio, A., Maglionico, M., Bolognesi, A. \& Artina, S. Toxicity and pollutant impact analysis in an urban river due to combined sewer overflows loads. Water Sci. Technol. 61, 207-215 (2010).

13. Eganhouse, R.P. \& Sherblom, P.M. Anthropogenic organic contaminants in the effluent of a combined sewer overflow: Impact on Boston Harbor. Mar. Environ. Res. 51, 51-74 (2001).

14. Even, S. et al. Modelling the impacts of combined sewer overflows on the river Seine water quality. Science Total Environ. $375,140-$ 151 (2007).

15. Phillips, P.J. et al. Combined sewer overflows: An environmental source of hormones and wastewater micropollutants. Environ. Sci. Technol. 46, 5336-5343 (2012).

16. Hammond, M.J., Chen, A.S., Djordjević, S., Butler, D. \& Mark, O. Urban flood impact assessment: A state-of-the-art review. Urban Water J. 12, 14-29 (2015).

17. Rosenzweig, B. et al. Developing knowledge systems for urban resilience to cloudburst events. Environ. Sci. Policy. 99, 150-159 (2019).

18. Simpson, P. Nat. Clim. Change. 4, 311-313 (2014).

19. Chini, C.M., Canning, J.F., Schreiber, K.L., Peschel, J.M. \& Stillwell, A.S. The green experiment: Cities, green stormwater infrastructure, and sustainability. Sustain. 9, 105 (2017).

20. Gaffin, S.R., Rosenzweig, C. \& Kong, A.Y.Y. Nat. Clim. Change. 2, 704 (2012).

21. Gaines, J.M. Flooding: Water potential. Nature 531, S54-S55 (2016).

22. Kabisch, N. et al. Nature-based solutions to climate change mitigation and adaptation in urban areas - perspectives on indicators, knowledge gaps, barriers and opportunities for action. Ecol. Soc. 21(2), (2016).

23. Li, H., Ding, L., Ren, M., Li, C. \& Wang, H. Sponge city construction in China: A survey of the challenges and opportunities. Water 9 , 594 (2017).

24. Brudler, S., Arnbjerg-Nielsen, K., Hauschild, M.Z. \& Rygaard, M. Life cycle assessment of stormwater management in the context of climate change adaptation. Water Res. 106, 394-404 (2016).

25. Brudler, S. et al. Life cycle assessment of point source emissions and infrastructure impacts of four types of urban stormwater systems. Water Res. 156, 383-394 (2019).

26. Albino, V., Berardi, U. \& Dangelico, R.M. Smart cities: Definitions, dimensions, performance, and initiatives. J. Urban Technol. 22, (2015).

27. Eggimann, S. et al. The Potential of knowing more: A review of data-driven urban water management. Environ. Sci. Technol. 51, 25382553 (2017).

28. Gourbesville, P. Editorial: Why smart water journal? Smart Water 1, 1-2 (2016).

29.German Water Partnership. WATER 4.0. Available at https://www.germanwaterpartnership.de/fileadmin/pdfs/gwp_materialien/GWP_ Brochure_Water_4.0.pdf, accessed online 31/5, 2018.

30. Sedlak, D. Water 4.0: The Past, Present, and Future of the World's Most Vital Resource (Yale University Press, 2014).

Page 11 of 13 
31. Andreja, R. Industry 4.0 concept: Background and overview. International Journal of Interactive Mobile Technologies 11, 77-90 (2017).

32. Kerkez, B. et al. Smarter stormwater systems. Environ. Sci. Technol. 50, 7267-7273 (2016).

33. García, L. et al. Modeling and real-time control of urban drainage systems: A review. Adv. Water Resour. 85, 120-132 (2015).

34. Gaborit, E., Anctil, F., Pelletier, G. \& Vanrolleghem, P.A. Exploring forecast-based management strategies for stormwater detention ponds. Urban Water J. 13, 841-851 (2016).

35. Quigley, M. \& Brown, C. Transforming Our Cities: High-Performance Green Infrastructure. WERF Report INFR1R11 (Water Environment Research Foundation, USA, 2014).

36. Lerer, S.M., Righetti, F., Rozario, T. \& Mikkelsen, P.S. Integrated hydrological model-based assessment of stormwater management scenarios in Copenhagen's first climate resilient neighbourhood using the three point approach. Water 9, 883 (2017).

37. Fratini, C., Geldof, G.D., Kluck, J. \& Mikkelsen, P.S. Three points approach (3PA) for urban flood risk management: A tool to support climate change adaptation through transdisciplinarity and multifunctionality. Urban Water J. 9, 317-331 (2012).

38. Adams, C. Copenhagen Ranked Most Liveable City for Europeans (The Independent). Available at https://www.independent.co.uk/travel/news-and-advice/copenhagen-denmark-liveable-cities-europeans-eca-internationala8777806.html, accessed online 6/5, 2019.

39. Climate Change Adaptation and Investment Statement - Part 1 (City of Copenhagen, Denmark, 2015).

40. Madsen, H.M., Mikkelsen, P.S. \& Blok, A. Framing professional climate risk knowledge: Extreme weather events as drivers of adaptation innovation in Copenhagen, Denmark. Environ. Sci. Policy 98, 30-38 (2019).

41. Carr, R.W., Esposito, C. \& Walesh, S.G. Street-surface storage for control of combined sewer surcharge. J. Water Resour. Plann. Manage. $127,162-167$ (2001).

42. Walesh, S.G. Street Storage System for Control of Combined Sewer Surcharge. EPA/600/R-00/065 (U.S. Environmental Protection Agency, 2000).

43. Sörensen et al. Re-thinking urban flood management - Time for a regime shift. Water 8, 332 (2016).

44. Xu et al. Improving the multi-objective performance of rainwater harvesting systems using real-time control technology. Water 10, 147 (2018).

45. Bilodeau, K., Pelletier, G. \& Duchesne, S. Real-time control of stormwater detention basins as an adaptation measure in mid-size cities. Urban Water J. 15, 858-867 (2018).

46. Mullapudi, A., Wong, B.P. \& Kerkez, B. Emerging investigators series: Building a theory for smart stormwater systems. Environ. Sci: Water Res. Technol. 3, 66-77 (2017).

47. Vezzaro, L., Christensen, M.L., Thirsing, C., Grum, M. \& Mikkelsen, P.S. Water quality-based real time control of integrated urban drainage systems: A preliminary study from Copenhagen, Denmark. Procedia Eng. 70, 1707-1716 (2014).

48. Chen, P. et al. Scenario simulation-based assessment of trip difficulty for urban residents under rainstorm waterlogging. Int. J. Environ. Res. Public Health 9, 2057-2074 (2012).

49. Pregnolato, M., Ford, A., Wilkinson, S.M. \& Dawson, R.J. The impact of flooding on road transport: A depth-disruption function. Trans. Res. D 55, 67-81 (2017).

50. Wong, T.H.F \& Brown, R.R. The water sensitive city: principles for practice. Wat. Sci. Tech. 60, 673-682 (2009).

51. Henonin, J., Russo, B., Mark, O. \& Gourbesville, P. Real-time urban flood forecasting and modelling - a state of the art. J. Hydroinform. 15, 717-736 (2013).

52. Madsen, H., Falk, A.K. \& Halvgaard, R. A model predictive control framework for real-time optimisation of water system operations. In Proceedings of the $13^{\text {th }}$ International Conference on Hydroinformatics, Palermo, Italy 3, 1281-1288 (2018). https://doi.org/10.29007/fg7g

53. Thorndahl, S. et al. Weather radar rainfall data in urban hydrology. Hydrol. Earth Syst. Sci. 21, 1359-1380 (2017).

54. Leth, C. \& Christensen, P.E. Cloudburst Valve. DK178640B1 (Patent og Varemærkestyrelsen, Denmark, 2016).

55. Middelfart Municipality. The waterway - new paths for rainwater in Middelfart. Available at https://climatelab.middelfart.dk/Waterway, last accessed 10/5, 2019.

56. Elmqvist et al. Sustainability and resilience for transformation in the urban century. Nat. Sustain. 2, 267-273 (2019).

57. Hann et al. The needs of society: A new understanding of transitions, sustainability and liveability. Technol. Forecast. Soc. Change 85 , 121-132 (2014).

58. World Urbanization Prospects: The 2018 Revision (United Nations Department of Economic and Social Affairs, 2018).

59. Halvgaard, R., Vandenberghe, L., Poulsen, N.K., Madsen, H. \& Jørgensen, J.B. Distributed model predictive control for smart energy systems. IEEE T. Smart Grid 7, 1675-1682 (2016).

60. Kamal, A.S., Imura, J.-I., Hayakawa, T., Ohata, A. \& Aihara, K. Smart driving of a vehicle using model predictive control for improving traffic flow. IEEE T. Intell. Transp. 15, 878-888 (2014).

Page 12 of 13 


\section{Author contributions}

N.S.V.L., M.B. and P.S.M. came up with the initial concept, which was further refined in collaboration with the remaining coauthors. N.S.V.L. and M.B. designed the experiment, and N.S.V.L. performed the simulations and drafted the first version of the paper. All authors contributed to the interpretation of the results and the writing and editing of the manuscript. N.S.V.L. revised the manuscript, mainly with assistance of K.A.-N. and P.S.M. All authors approved the revisions.

\section{Additional information}

Correspondence should be addressed to N.S.V.L. (nalu@env.dtu.dk) or P.S.M. (psmi@env.dtu.dk).

\section{Acknowledgements}

The authors would like to thank Rasmus Halvgaard and Anne Katrine Falk from DHI for the many inspiring discussions over the past years, and the Greater Copenhagen Utility Company (HOFOR) for access to a 1D hydrodynamic model for the case area. We acknowledge financial support from Realdania through the "Klimaspring" programme as part of the "Smart Cities Water Solutions" project, and from Innovation Fund Denmark through the "Water Smart Cities" project. We finally thank three anonymous reviewers for their constructive comments.

\section{Competing interests}

The authors declare no competing interests. 